A s questões relativas à identificação e atendimento ao superdotado (1) têm sido objeto de uma atenção crescente em países dos mais diversos continentes. Esta atenção reflete a consciência de que o potencial superior é um dos recursos naturais mais preciosos, responsável pelas contribuiçōes mais significativas ao desenvolvimento de uma civilização. Neste sentido, Sternberg \& Davidson (1986) destacam, por exemplo, que, quando se volta à História e se buscam os pilares das grandes civilizaçōes, inevitavelmente as contribuiçōes artisticas, filosóficas e científicas, fruto da inteligência, talento e criatividade de alguns indivíduos ou grupos de indivíduos, são apontadas ou enaltecidas. Observa-se, entretanto, que o interesse por aqueles homens e mulheres dotados de uma habilidade superior sempre existiu em diferentes sociedades. Há vários registros históricos indicando, por exemplo, diferentes momentos em que este interesse veio à tona, como nas propostas de Platão, que defendia a idéia de que aqueles indivíduos com inteligência superior deveriam ser selecionados nos seus primeiros anos de infância e suas habilidades cultivadas em benefício do Estado.

Também há registros de um sistema de exames competitivos elaborado pelos chineses há mais de 2000 anos antes de Cristo, para selecionar crianças que se destacavam por sua inteligência superior, as quais passavam a receber um atendimento especial. Estas crianças eram denominadas "divinas" e encaminhadas à corte, tidas como presságio de prosperidade nacional. Especialmente a imaginação criadora que se manifestava através da poesia e ensaios era altamente valorizada. Na literatura chinesa, não é raro encontrar referências, especialmente a crianças com habilidades excepcionais. Um exemplo seria Li Bai, um famoso poeta chinês, que memorizou a obra de Confúcio quando tinha 5 anos ou Quan $\mathrm{De} \mathrm{Yu}$, que começou a escrever poesia aos 4 (Kwok, sem data).

É o objetivo do presente texto discutir alguns aspectos relativos à identificação e atendimento ao superdotado, com vistas a apontar sobretudo para a necessidade de se implementar no Brasil uma educação que atenda também às necessidades daqueles alunos que se destacam por um potencial superior.

É notório que há uma enorme resistência à implementação de um atendi-

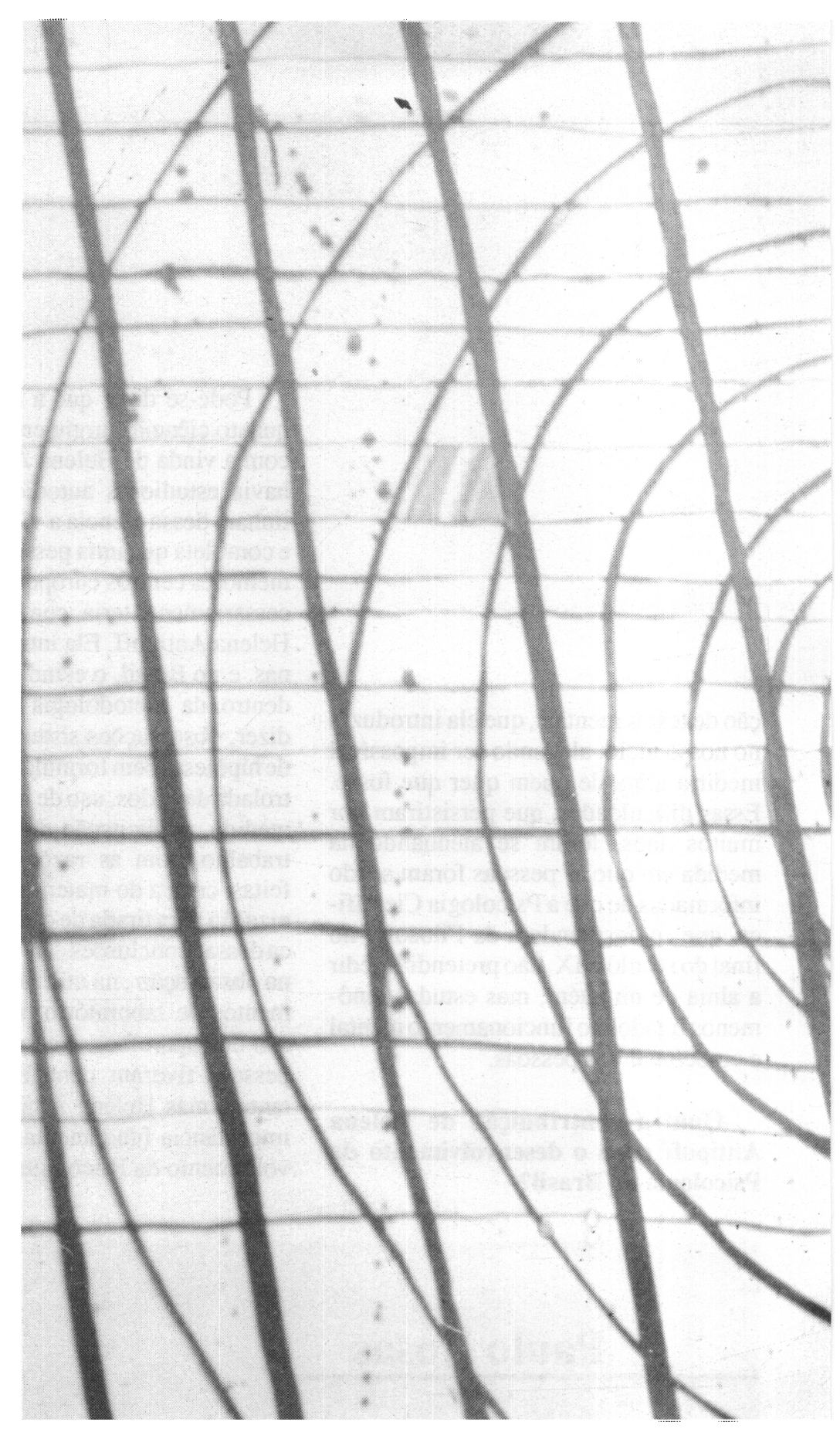

\title{
A identificaçãc
}
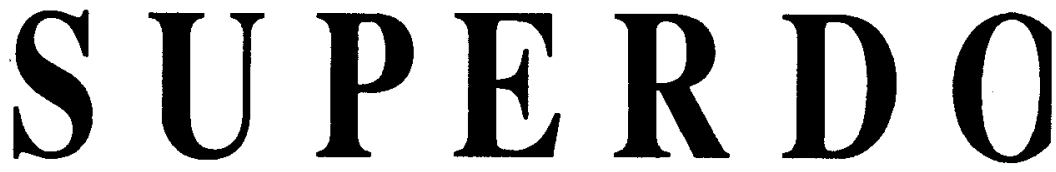


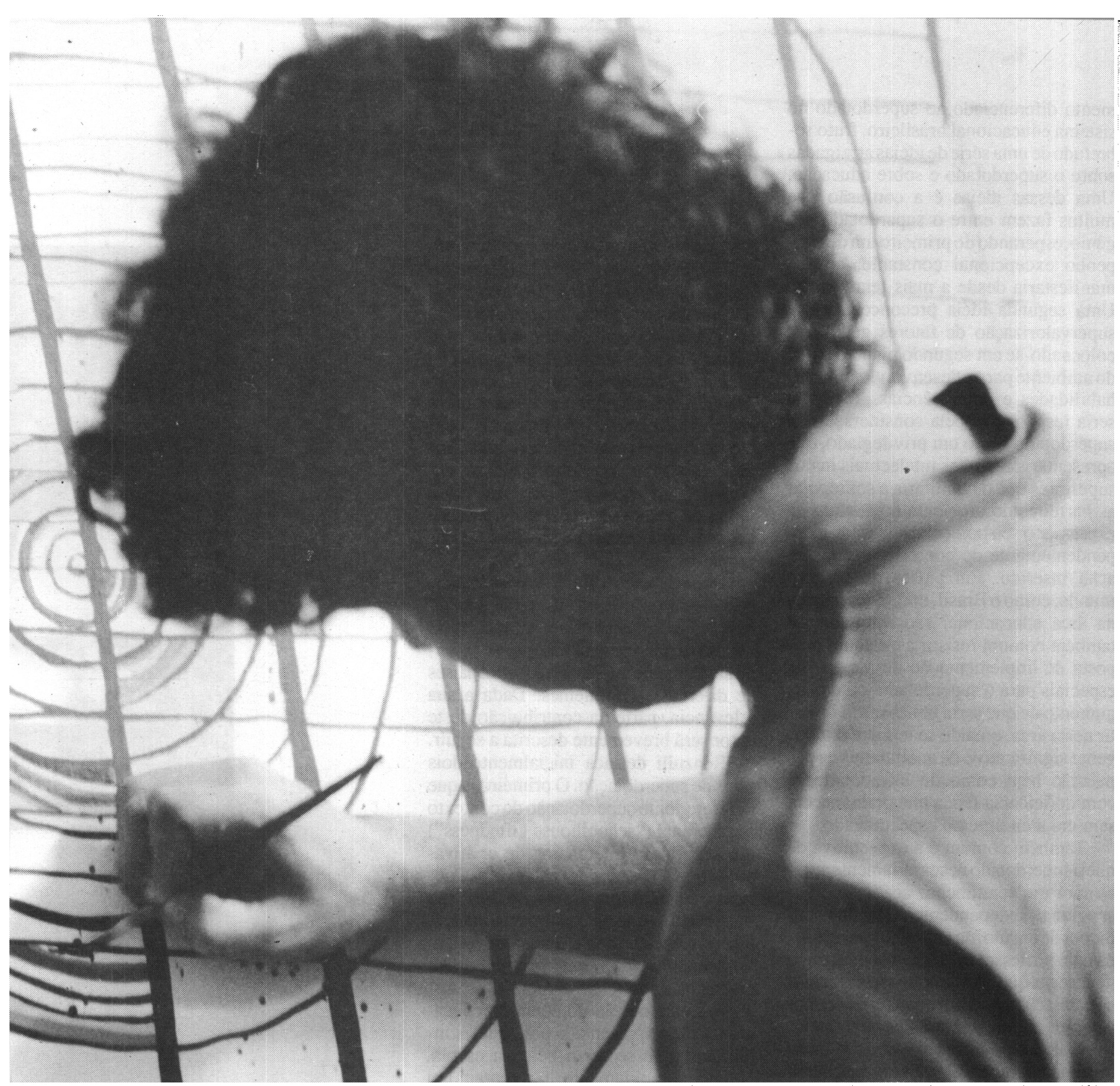

\section{e 0 atendimento ao}

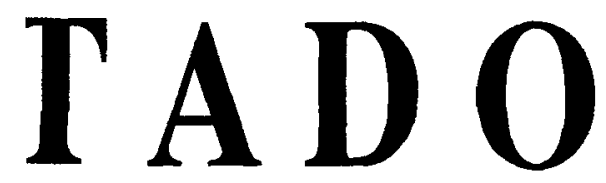

Eunice M. L. Soriano de Alencar

Professora do Instituto de Psicologia
da UNB 
mento diferenciado ao superdotado no sistema educacional brasileiro, fruto sobretudo de uma série de idéias arraigadas sobre o superdotado e sobre educação. Uma dessas idéias é a confusão que muitos fazem entre o superdotado e o gênio, esperando do primeiro um desempenho excepcional constante, que se manifestaria desde a mais tenra idade. Uma segunda idéia preconcebida é a supervalorização de fatores genéticos, colocando-se em segundo plano o papel do ambiente para o desenvolvimento das habilidades e competências. Tal idéia seria responsável pela consideração do superdotado como um privilegiado, que apresentaria recursos intelectuais inatos superiores que o habilitaria a sobrepujar as barreiras do ambiente no sentido de expressar o seu potencial superior, independentemente do contexto em que se acha inserido. Em países do terceiro mundo, como o Brasil, onde as carências na área educacional são ilimitadas, é também comum resistir a qualquer proposta de implementação de programas especiais para o superdotado, com o argumento de que seria um absurdo investir nesta área, quando se tem um contingente significativo de analfabetos na população bem como de infradotados e com deficiência física que permanecem sem um atendimento especializado.

Também comum é a expectativa de que o superdotado necessariamente apresentará um rendimento acadêmico excepcional, independentemente das condições de ensino, da metodologia utilizada pelo professor e das pressðes de grupo de colegas que comumente são exercidas com relação ao aluno que se destaca por suas idéias ou habilidades marcantes. Estas e outras idéias errôneas (2) estão profundamente enraizadas no pensamento popular, fruto da ignorância, preconceito tradição, interferindo e dificultando a implantação de programas para o superdotado.

\section{Conceituação}

$O$ ponto de partida para uma discussão sobre identificação e atendimento ao superdotado reside necessariamente na conceituação dos construtos superdotado e superdotação. Observa-se que esta questão tem sido objeto de numerosas điscussões, com inúmeras abordagens e concepçð̄es.

Sternberg \& Davidson (1986), no livro de sua autoria "Concepções da Superdotação" apresentam, por exemplo, 17 concepçōes distintas da superdotação. Estas refletem abordagens psicológicas e enfoques teóricos bastante diversifica- dos, como a apresentada por Renzulli (1986), Feldhusen (1986), Csikszentmihalyi \& Robinson (1986), Gardner (1983) e Tannenbaum (1983). Uma análise destas diferentes concepções indica uma ênfase às vezes no indivíduo, outras na sociedade; no domínio psicológico ou no domínio educacional; em componentes cognitivos apenas ou nas dimensóes cognitivase de personalidade. Estas diferentes concepções interrelacionam-se, entretanto, em alguns pontos, sugerindo linhas de pesquisas que certamente contribuem para testar as diversas teorias propostas.

Dentre estes diferentes enfoques, destaca-se o de Renzulli, cujas contribuições teóricas se aliam a práticas de identificação e programas que vêm sendo amplamente implementadosem países de diferentes continentes. Dada a sua relevância, parte da contribuição deste autor será brevemente descrita a seguir.

Renzulli destaca inicialmente dois tipos de superdotação. O primeiro, a que se refere como superdotação do contexto educacional ("schoolhouse giftedness") e o segundo a que chama de criativaprodutiva ("creative-productive"). Considera também que ambos os tipos são importantes, que há usualmente interrelações entre os dois e que se deveriam implementar programas para encorajar ambos os tipos.

A superdotação do contexto educacional seria apresentada por aqueles indivíduos que se saem bem na escola, aprendem rapidamente, apresentam um nível de compreensão mais elevado e têm sido os indivíduos tradicionalmente selecionados para participar de programas especiais.

O segundo tipo de superdotação, a que se refere como criativa-produtiva, diz respeito aqueles aspectos da atividade humana onde se valoriza o desenvolvimento de produtos originais. Observa Renzulli que as situações de aprendizagens planejadas para se promover este tipo de superdotação enfatizam o uso e aplicação da informação e os processos de pensamento de uma maneira integrada, indutiva e orientada para problemas reais, distinguindo-se daquelas situaçðes que visam promover a superdotação do primeiro tipo, uma vez que esta tende a enfatizar a aprendizagem dedutiva, o treino estruturado no desenvolvimento de processos de pensamento
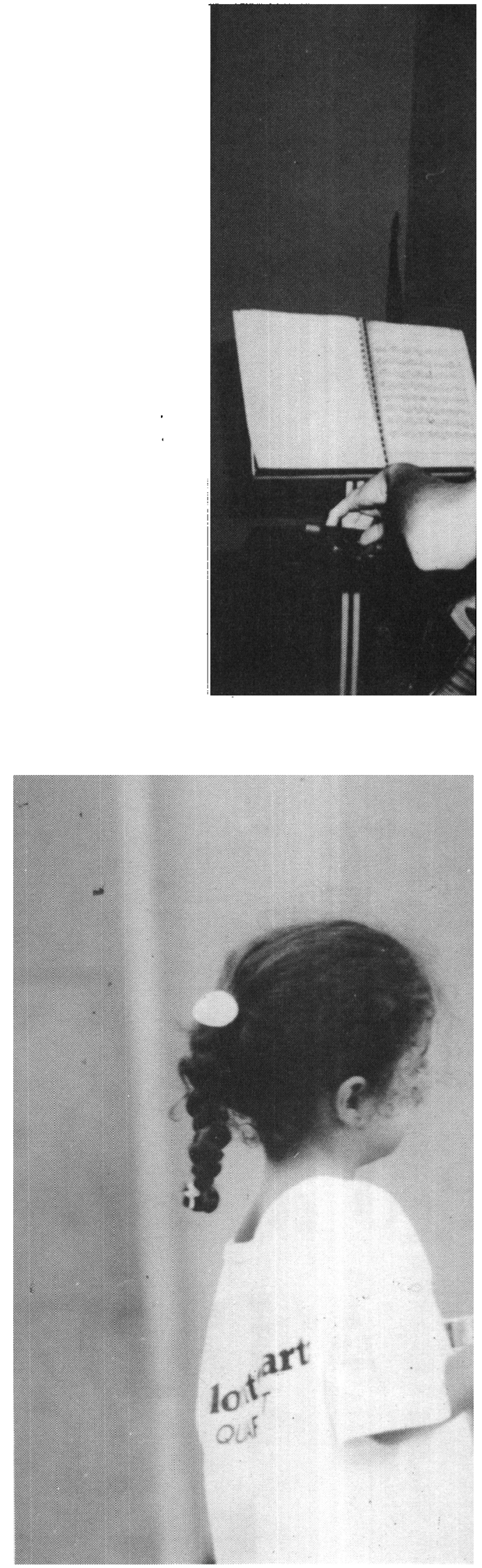


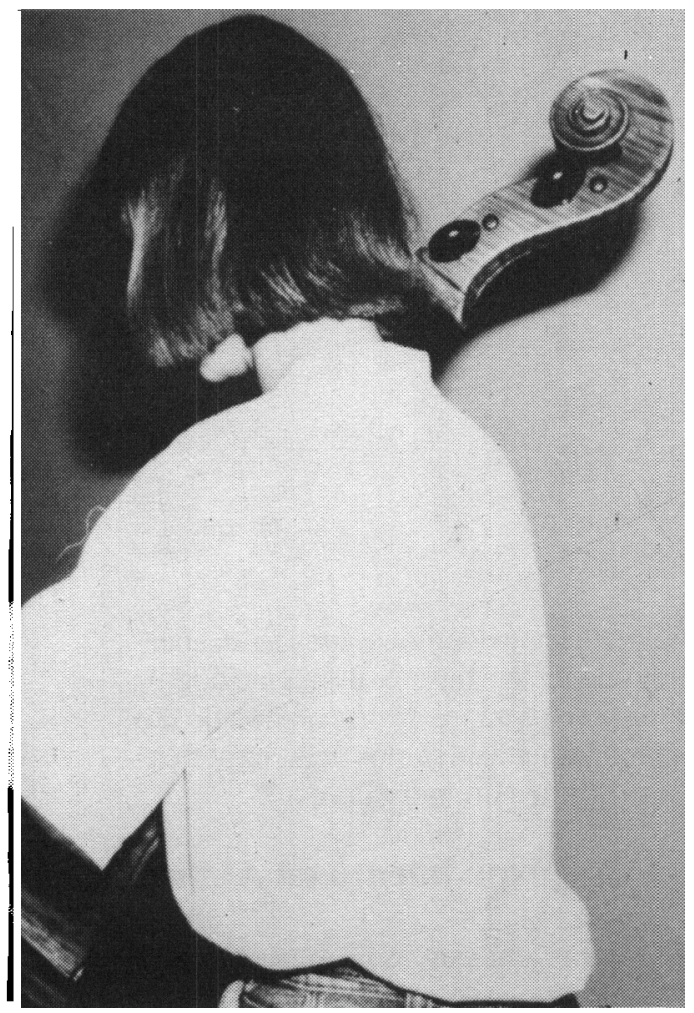

ea aquisição, armazenagem e reprodução da informação.

Renzulli interessou-se especialmente pelo segundo tipoe,com base em pesquisas sobre pessoas que haviam se destacado por suas realizaçôes e contribuiçðes criativas, propôs a sua concepção de superdotação, que engloba os seguintes aspectos: habilidade bem acima da média, envolvimento com a tarefa a criatividade.

\section{Superdotado}

- Habilidade acima da média

- Envolvimento com a tarefa - Criatividade

O primeiro aspecto englobaria tanto habilidade geral como habilidades específicas. A primeira consistiria na ca-

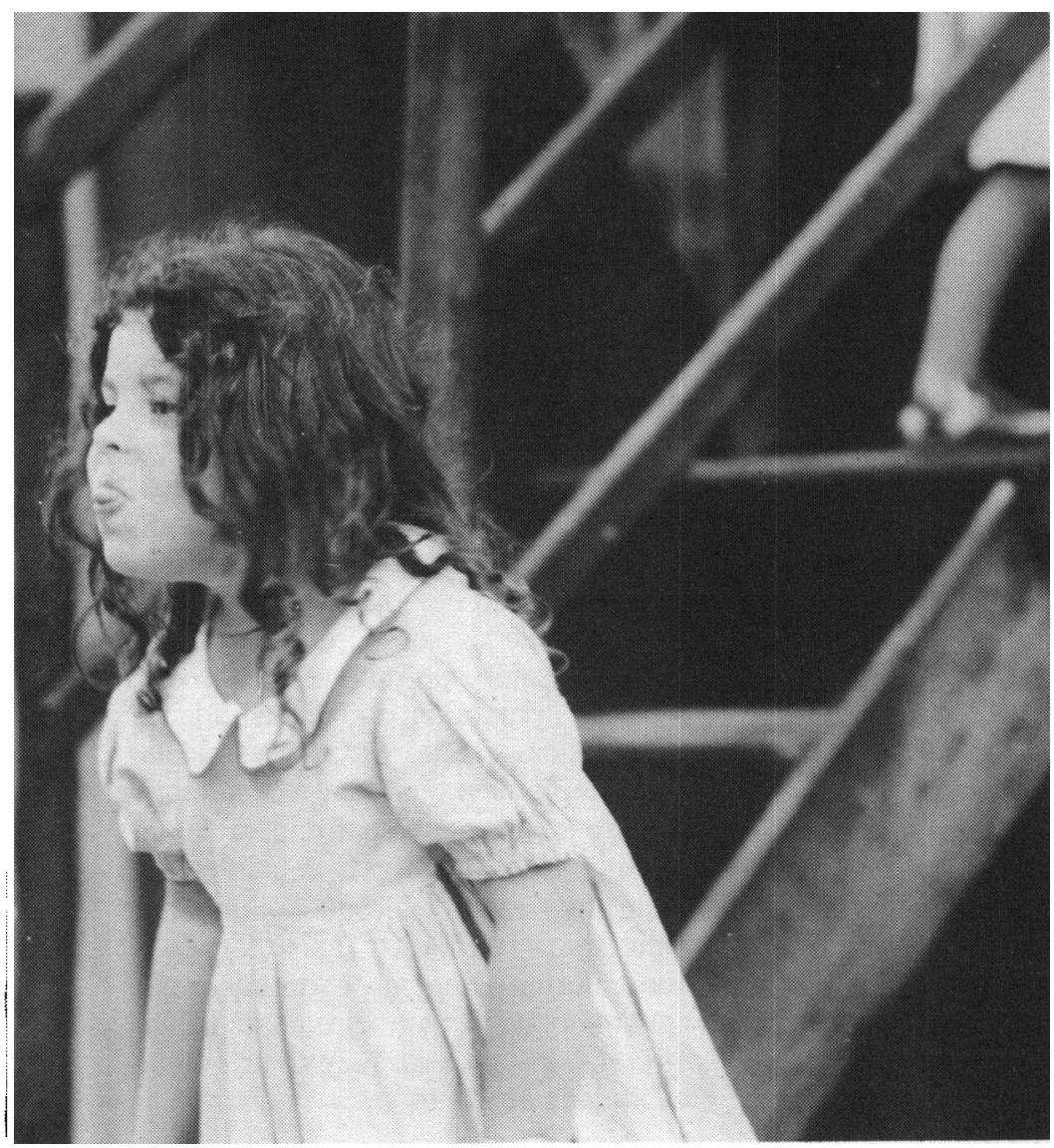

pacidade de processar informações, integrar experiências e se engajar em pensamento abstrato. As habilidades especificas consistiriam na capacidade de adquirir conhecimento, destreza ou habilidade para realizar uma ou mais atividades do tipo especializado. Renzulli dá como exemplos de habilidades específicas o balé, escultura, fotografia, química e matemática.

Envolvimento com a tarefa - constitui-se no componente motivacional e representaria a energia que o indivíduo canaliza para resolver um dado problema ou uma dada tarefa. Inclui traços como perseverança, dedicação, esforço, autoconfiança, e a crença na própria habilidade de desenvolver um importante trabalho.

Com relação à criatividade, um dos aspectos também presentes na concepção de superdotação apresentada, Renzulli chama a atenção para as limitaçōes inerentes aos testes de criatividade, sugerindo uma análise dos produtos criativos do sujeito como preferível a uma análise de seu desempenho em testes de criatividade.

Uma descrição detalhada das diferentes concepçðes de superdotação foge aos objetivos do presente texto. Por esta razão, limitar-nos-emos a sugerir a leitura da literatura pertinente e especialmente do tex to de Sternberg \& Davidson (1986), lembrando que algumas destas concepçð̄es foram derivadas de teorias da inteligência, como, por exemplo, da teoria das múltiplas inteligências propostas por Gardner (1983) e a teoria triárquica da inteligência proposta por Sternberg (1985).

É necessário lembrar ainda que a visăo da superdotação como composta por muitas facetas tem sido ponto de vista comum entre os estudiosos do assunto, que apontam para uma diversidade de talentos que estariam incluídos no termo SUPERDOTADO. Esta é a perspectiva adotada oficialmente no Brasil, onde a seguinte definiçăo tem sido divulgada nos documentos oficiais do $\mathrm{Mi}$ nistério da Educação:

"Säo consideradas crianças superdotadas e talentosas as que apresentam notável desempenho elou elevadapotencialidade em qualquer dos seguintes aspectos, isolados ou combinados:

- capacidade intelectual superior

- aptidão acadêmica específica

- pensamento criador ou produtivo - capacidade de liderança

- talento especial para artes visuais, artes dramáticas e música

. capacidade psicomotora" 
Esta definiçãa tem sido, porém, criticada por alguns estudiosos da área, como Renzulli, especialmente pelo fato de a mesma não incluir fatores motivacionais e pela natureza não parelela das seis categorias. Neste sentido, Renzulli afirma:

"Duas entre as seis categorias (aptidāo acadêmica $e$ artes) chamam a atenção para os campos de atividade humana ou áreas de desempenho nas quais os talentos e habilidades se manifestam. As quatro categorias restantes aproximam-se mais de processos que podem se manifestar emáreas de desempenho. Por exemplo, uma pessoa pode utilizar o processo de criatividade com relação a uma aptidão específica (como química) ou arte visual (como fotografia). De forma similar, os processos de liderança e inteligência geral podem ser aplicados em uma área de desempenho como coreografia... De fato, pode ser dito que processos como criatividade e liderança não existem à parte de uma área de desempenho a que podem ser aplicados" (Renzulli, 1986).

\section{Processos de Identificação}

Vários são os aspectos que têm sido apontados com relação à identificação. Um deles é o ponto de vista de vários especialistas que consideram a definição adotada de superdotado como o fator determinante do procedimento utilizado na identificação. Isto justificaria o processode identificação em vigor na primeira metade deste século, quando o superdotado era definido como aquele indivíduo com um $\mathrm{QI}$ superior, e quando o processode identificação se reduzia simplesmente na aplicação de um teste de inteligência geral, como o Stanford-Binet, ou o Teste de Matrizes Progressivas de Raven.

Em décadas mais recentes, a natureza multidimensional do conceito passou a ser enfatizada, passando os responsáveis pelos programas para o superdotado a utilizar uma multiplicidade de procedimentos, como testes de inteligência, criatividade, dados sobre o rendimentoacadêmico, complementadoscom a observação do professor e questionários e escalas respondidos pelo próprio aluno.

Nas duas últimas décadas, várias escalas foram também desenvolvidas para

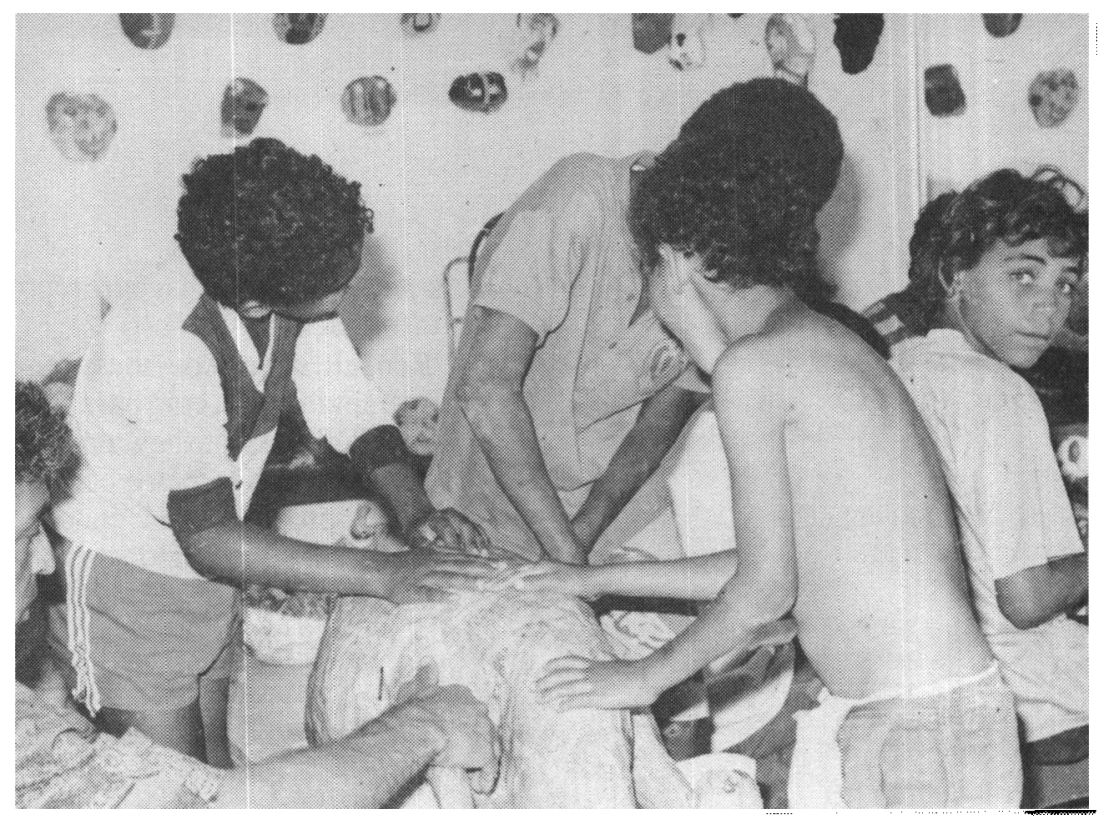

serem utilizadas pelos professores com vistas a estimar as características do aluno nas áreas de aprendizagem, motivação, criatividade, liderança. Como se sabe, em algumas áreas como criatividade, várias limitações inerentes aos testes têm sido apontadas, o que tem levado os especialistas a sugerir métodos alternativos de identificação dos alunos mais criativos.

Também passou-se a considerar que a identificaçăo deveria variar conforme as caracteristicas e objetivos do programa proposto para o superdotado. Desta forma, em um programa naárea artística, a identificação certamente implicará em uma metodologia que avalia aspectos diversos do talento em questão. De forma similar, se a proposta do programa é atender aqueles alunos que se destacam na área de matemática ou ciências, isto irá implicar na identificação de habilidades específicas relativas a estas áreas. Por outro lado, se a proposta é identificar alunos universitários que se destacam por suas habilidades superiores, naturalmente o procedimento de seleção e identificação será certamente diferente daquele proposto para alunos da pré-escola ou primeiro grau.

De forma similar, para a identificação de alunos com um potencial superior provenientes do meio rural ou das camadas mais pobres da população, cuidados especiais devem ser tomados, uma vez que os testes e outros instrumentos de identificação disponiveis são mais adequados para a população de classe média. Neste grupos, grau de interesse e motivação, originalidade de pensamento, além de traços de personalidade, como iniciativa e persistência, devem ser espe- cialmente considerados, apesarde sabermos que tanto o desenvolvimento cognitivo como os traços de personalidade são profundamente afetados pelas experiências culturais do indivíduo.

\section{O Desenvolvimento do Aluno}

Muitas têm sido as propostas implementadas por sistemas educacionais de diferentes países para atender ao aluno que se destaca por suas habilidades superiores ${ }^{(3)}$. Estas se enquadram tradicionaImente em três grandes grupos - enriquecimento, aceleração e segregação levadas a efeito tanto na própria escola onde o aluno estuda, como em outros locais disponíveis, como em museus ou universidades. Nota-se ainda que, em vários países, muitos dos programas montados têm sido em áreas consideradas prioritárias pelo Estado, como Matemática e Ciências. A título de ilustração, poder-se-ia lembrar o programa de Ciências que é oferecido na Universidade de Colúmbia, nosEstados Unidos, para 500 alunos do ensino de segundo grau, que se destacam por seu desempenho acadêmico e que são convidados a participar de cursos e seminários aos sábadós. Também muito conhecido é o programa para alunos com habilidades matemáticas superiores na Universidade John Hopkins, o qual tem recebido crianças e jovens que aí participam de um programa de alto nível. É o interesse deste programa atender àquele alunocom raciocínio matemático mais elevado e que tenha um potencial de se transformar em um notável engenheiro, matemático ou cientista, em áreas que exijam grande habilidade quantitativa. 
Outro exemplo são os programas que têm sido oferecidos no Instituto para a Promoção de Artes e Ciências, ligado ao Museu Haaretz eà Universidade de TelAviv, em Israel, onde anualmente várias centenas de crianças e jovens têm tido oportunidade de desenvolver as suas habilidades e talentos, através de cursos que enfatizam sobretudo a criação de idéias. Este Instituto vem oferecendo uma grande diversidade de cursos, desde a sua fundação, utilizando como um dos critérios para participação nos mesmos resultados superiores em testes de inteligência.

As escolas especiais para talentos acadêmicos, como aEscola de Matemáticae Ciências de Moscou, subvencionada pela Universidade de Estado de Moscou, juntamente com os Jogos Olímpicos ligados às matérias escolares - Matemática, Física, Química, Biologia, Literatura - e várias das atividades desenvolvidas nas Casas e Círculos dos Pioneiros, ilustram as provisões levadas a efeito na Rússia.

No Brasil, há vários programas para o superdotado. Em Brasília, por exemplo, a Fundação Educacional do Distrito Federal deu início em 1975 a um programa para alunos superdotados do ensino de primeiro grau, que inclui atividades de enriquecimento e aprofundamente curricular. Também em Minas Gerais, um programa de atendimento ao aluno superdotado do meio rural e periferia urbana foi iniciado pela professora $\mathrm{He}$ lena Antipoff, no início da década de 70, programa que vem sendo coordenado pelo professor Daniel Antipoff. As atividades propostas neste programa têm sido sobretudo durante as férias. Elas visam o enriquecimento das experiências do aluno e o desenvolvimento de suas habilidades, canalizando os seus interesses e curiosidade através de investigaçōes e experiências.

Quanto aos objetivos propostos para os diversos programas, alguns dos que têm sido usualmente encontrados são apresentados a seguir:

. Ajudar aqueles indivíduos, com um alto potencial, adesenvolver ao máximo os seus talentos e habilidades;

. Fortalecer um autoconceito positivo;

.Ampliar as experiências desses alunos em uma diversidade de áreas;

. Desenvolver no aluno uma consciência social;

- Incrementar um clima de aprendizagem que resulte em maior produtividade;

. Favorecer o ajustamento pessoal e social.
De forma similar, algumas características têm sido consideradas como importantes de serem apresentadas pelos professores responsáveis pela implementação do programa. Algumas destas características são: boa preparação; experiência de ensino; criatividade e flexibilidade; senso de humor; confiança nos alunos; entusiasmo.

Especialmente a preparação dos professores para atender adequadamente a este grupo de alunos tem recebido uma grande atenção. É relevante lembrar que não basta que o professor domine a sua área de conhecimento. É importante que ele utilize também estratégias que favoreçam o desenvolvimento integral do aluno, que possibilite o treino de habilidades cognitivas diversas, criando ainda em sala de aula um ambiente favorável à exploração e à descoberta, à produção de idéias e de conhecimento.

Para finalizar, é necessário destacar a necessidade de uma maior divulgação entre educadores e psicólogos brasileiros do enorme desperdício de talento e potencial humano em nosso País decorrente de uma visão limitada de educação e das poucas possibilidades oferecidas ao desenvolvimento e expressão da inteligência, da criatividade e do talento. Vivemos em um momento da História caracterizado por uma necessidade crescente de indivíduos com competência acentuada nas mais diversas áreas. São os superdotados aqueles que certamente maiores contribuiçőes poderão dar à sociedade, desde que sejam reconhecidos, identificados e tenham o seu potencial superior desenvolvido e aproveitado. Cabe a todos nós, psicólogos e educadores, contribuir para que isto se concretize.

\section{Notas}

(1) Este texto se baseia em uma palestra proferida durante o $1^{*}$ Congresso Nacional de Psicologia Escolar, emnovembro de 1991. Estáprevista a sua publicação nos anais desse evento.

(2) Discuto as diversas idéias errôneas sobre o superdotado no texto de minha autoria "Psicologia e Educaçäo do Superdotado" (Alencar, 1986).

(3) As idéias aqui contidas foram apresentadas no artigo "O Estimulo ao Talento è à Excelência" (Alencar, 1986).

\section{Bibliografia}

ALENCAR, E.MLS. (1986). Psicologia e Educação do Superdotado. Sāo Paulo, EPU.

ALENCAR, E.ML.S. (1988). O Estímulo ao Talento e à Excelência. In: Jornal de Psicologia, 7(3), 10-13.

CSIKSZENTMIHALYI,M.\& ROBINSON, R.E. (1986). Culture, Time and the Development of Talent. $E m R$. J. Sternberg \& J.B. Davidson (Eds), Conceptionof Giftedness. Cambridge: Cambridge University Press.

FELDHUSEN, JJ.(1986). A Conception of Giftedness. Em R. R. Stermberg \& JB. Davidson (Eds), Conceptios of Giftedness. Cambridge: Cambridge University Press.

GARDNER, J. (1983). Frames of Mind. New York: Basic Books.

$K W O K, C$. (sem data). Gifted and Talented Education in China. From Ancient to Modern Times.Hong Kong: Kwok.

RENZULLI,JS.(1986).The ThreeRing Conception of Giftedness: $A$ Developmental Model for Creative Productivity. Em R.J. Stermberg \& J.B. Davidson (Eds), Conceptions of Giftedness. Cambridge: Cambridge University Press.

STERNBERG,R.J.(1985).Beyond IQ.A Triachic Theory of Intelligence. Cambridge: Cambridge University Press.

STERNBERG,R.J.\& DAVIDSON, J.B. (1986). Conceptions of Giftedness. Cambridge: Cambridge University Press.

TANNEMBAUM, A. (1983). Gifted Children. Psychological and Educational Perspectives. New York, Macmillan Publishing Co. 